\title{
Çukurova Koşullarında Farklı Yonca (Medicago sativa L.) Genotiplerinin Klonal Yolla Çoğaltılması Üzerine Bir Araştırma
}

\author{
Mustafa AVCI ${ }^{1} \quad$ Rüstü HATIPOĞLU ${ }^{2} \quad$ Selahattin ÇINAR $^{3} \quad$ Celal YÜCEL $^{4}$ İlker INAL ${ }^{4}$ \\ Arif AKTAŞ ${ }^{4} \quad$ Feyza GÜNDEL ${ }^{4} \quad$ Hatice YÜCEL ${ }^{4}$ \\ ${ }^{1}$ Niğde Ömer Halisdemir Üniversitesi, Tarım Bilimleri ve Teknolojileri Fakültesi, Niğde. \\ ${ }^{2}$ Çukurova Üniversitesi Ziraat Fakültesi, Tarla Bitkileri Bölümü, Adana. \\ ${ }^{3}$ Kilis 7 Aralık Üniversitesi, Meslek Yüksek Okulu, Kilis. \\ ${ }^{4}$ Doğu Akdeniz Tarımsal Araştırma Enstitüsü Müdürlüğü, Adana. \\ $\varangle$ : mavci61@ hotmail.com
}

Geliş (Received): 02.11.2017

Kabul (Accepted): 15.12.2017

\begin{abstract}
ÖZET: Bu araştırma, Doğu Akdeniz Tarımsal Araştırma Enstitüsü Müdürlüğü’nde yürütülen Yonca Islah Araştırmaları projesi kapsamında çeşit geliştirme amacıyla seçilen 16 farklı yonca genotipinin klonal yolla çoğaltılmasında uygun yöntemin tespit edilmesi amacıyla yürütülmüştür. Klonal çoğaltma işlemleri tarla koşullarında ve kum havuzunda olmak üzere iki ortamda yürütülmüştür. Araştırmada yer alan genotiplerin sap parçaları (basit çelik) ve kök tacı sürgünleri (ökçeli çelik) 2010 yılı Nisan ayı içerisinde Indole 3 Butirik Asit (IBA) çözeltisi uygulayarak ve IBA uygulanmadan dikilmişlerdir. Dikim alanlarında tutan ve tutmayan klonların sayım işlemi yapılımıştır. Araştırma bulguları uygulamalar ve genotipler arasında istatistiksel olarak çok önemli farkların olduğunu göstermiştir. Araştırma sonuçlarına göre, Çukurova ekolojik koşullarında yoncanın klonal yolla çoğaltılmasında kum ortamında sap parçaları, tarla koşullarında ise kök tacı sürgünlerine IBA uygulandıktan sonra dikilmesinin incelenen genotiplerde köklenme oranını önemli derecede artırdığı ve bu uygulamaların yoncanın klonal çoğaltılmasında kullanılabileceği sonucuna varılmıştır.
\end{abstract}

Anahtar Kelimeler: yonca, klon, IBA, kum, toprak

\section{A Research on the Clonal Propagation of Different Alfalfa Genotypes under Çukurova Conditions}

ABSTRACT: This research was carried out in order to determine the appropriate method for the clonal propagation of 16 different alfalfa genotypes selected for variety development in the Alfalfa Breeding Project conducted in the Eastern Mediterranean Agricultural Research Institute. Clonal propagation was performed simultaneously in both the field conditions and the sand pool. Stem pieces or root crown shoots of the genotypes used in the study were planted in April in 2010 as treated with Indole 3 Butyric Acid (IBA) and IBA free. Numbers of the clones with rooted and non-rooted were determined. Research findings showed that there were statistically significant differences among the practices and genotypes. According to the results of the research, it was concluded that the application of IBA to stem pieces in the sand environment and to root- crown shoots in field conditions increased the rooting rate significantly, and these applications could be used in the clonal propagation of alfalfa under Çukurova conditions.

Key words: alfalfa, clone, IBA, sand, soil

\section{GİRIŞ}

Yem bitkilerinin kraliçesi olarak tanımlanan yonca, dünyada ve Türkiye'de yetiştirilen en önemli baklagil yem bitkisidir. $\mathrm{Bu}$ değerli yem bitkisinin ülkemizdeki tarımı giderek yaygınlaşmaktadır. $\mathrm{Bu}$ durum mevcut yonca çeşitlerine ek olarak ülkemizin farklı ekolojik koşulları için yüksek ve kaliteli ot üreten yeni yonca çeşitlerinin geliştirmesini gerektirmektedir. Yonca islah çalışmalarının farklı aşamalarında ümitvar yonca genotiplerinin klonal çoğaltmasına gereksinim duyulmaktadır. Ayrıca, yem bitkisi 1slahçıları, üstün bitkilerin çoğaltılması, sentetik çeşit oluşturulması, orijinal genotiplerin muhafazası, tohum üretimi yetersiz olan çeşitlerin çoğaltılması amaciyla vejetatif yolla çoğaltma işleminden faydalanmaktadırlar. Busbice ve ark. (1972), yabancı çiçek tozuyla tozlanan yoncada ot verimi gibi birçok gen çifti tarafindan kontrol edilen ve düşük kalıtım derecesine sahip karakterlerin izole edilmesinde klonlamanın büyük avantaj sağlayacağını açıklamışlardır. Bernadette ve ark. (2000), Fransa koşullarında yürüttükleri bir araştırmada yonca genotiplerini klonal yolla kum havuzunda köklendirdikten sonra tarlaya taşıdıklarını ve bunların oldukça gümrah gelişme gösterdiklerini bildirmiş̧lerdir. Araştırıcılar genotipler arasında köklenme veya klonal çoğalma yönünden önemli farklar olduğunu ve bazı genotiplerin oldukça zayıf köklendiğini bildirmişlerdir. Avcı ve ark. (2011), Çukurova ekolojik koşullarında sentetik yonca çeşidi geliştirmek amaciyla yürüttükleri bir proje kapsamında yonca genotiplerini klonal yolla başarılı bir şekilde çoğalttıklarını belirtmişlerdir. Poehlman ve Sleper (1995), tek bitkiden (genotipten) aseksüel yollarla çoğaltılan bitki grubunun klon olarak tanımlandığını, birçok 
yem bitkisinin stolon, rizom, gövdeden alınan çelikler, bitki tacının parçalara ayrılması ve doku kültürü teknikleriyle eşeysiz olarak çoğaltılmaya uygun olduğunu belirtmişlerdir. Araştırıcılar, yonca, üçgül, gazal boynuzu ve bazı çok yıllık buğdaygil yem bitkilerinin gövdeden alınan çeliklerinin $+18-25^{\circ} \mathrm{C}$ 'de nemli kum ortamında kolaylıkla köklenebildiklerini açıklamışlardır. Çeliklerin bitki büyütme hormonları ile muamelesinin köklendirme işlemini teşvik ettiğini, ancak bu uygulamanın zorunlu olmadığını vurgulamışlardır. El-Tabbakh (1965), Arizona Üniversitesi'nde yürüttüğü araştırmada Indolasetik asit, Naftalenasetikasit, Indolbutürikasit, Giberellik asit ve 2,4D gibi farklı büyüme düzenleyicilerinin perlit ortamında farklı yonca genotiplerinin vejetatif yolla çoğaltılması üzerine etkilerini incelemiştir. Araştırma sonucunda IAA ve 2,4-D nin yonca genotiplerinin kök gelişimi açısından en iyi sonuçları verdiğini ve genotiplerin uygulamalara farklı tepkiler gösterdiğini belirlemiştir. Çukurova ekolojik koşullarında yürütülen bu araştırmada, yoncanın çeşit geliştirme ve çeşitleri oluşturan ebeveyn hatlarının yenilenmesi ve muhafazasında siklıkla kullanılan, klonal çoğaltma işleminde en uygun yöntemin tespit edilmesi amaçlanmıştır.

\section{MATERYAL ve METOT}

$\mathrm{Bu}$ araştırma, Doğu Akdeniz Tarımsal Araştırma Enstitüsü Müdürlüğü'nde yürütülen Yonca Islah Araştırmaları projesi kapsamında çeşit geliştirme amaciyla seçilen 16 farklı yonca genotipinin (37-12, $22-4,22-10,14-3,26-12,16-11,14-6,19-8,5-11,7-2$, $8-11,23-9,21-1,1-10,20-7$ ve 29-11) klonal yolla çoğaltılmasında uygun yöntemin tespiti amacıyla yürütülmüş̧ür. Deneme 12 tekrarlamalı olarak tesadüf parselleri deneme desenine uygun olarak 2010 yıli ilkbaharında kurulmuştur. Klonal çoğaltma işlemleri hem kum havuzu ve hem de tarla ortamında eş zamanlı olarak gerçekleştirilmiştir. Araştırma alanı toprağ yüksek oranda kil ve kireç içeren hafif alkali ve düşük organik madde içeriğine sahiptir. Dikim amacıyla oluşturulan kum havuzu ise $3.5 \times 2.5 \mathrm{~m}$ en ve boyunda, yüksekliği ise $25 \mathrm{~cm}$ olarak inşa edilmiştir. Kum havuzu inşaatlarda sıva kumu olarak tanımlanan yıkanmış ve elenmiş ince nehir kumu ile doldurulmuştur. Daha önceden 1slah amaciyla tek bitkiler olarak dikilen kaynak popülasyondan sslah amacına uygun olarak tespit edilmiş 16 genotipten önce kök tacından sürgünler alınmış, aynı sürgünün taca bağlandığı kısım (ökçeli çelik) yaklaşı $20 \mathrm{~cm}$ uzunlukta kesilerek dikim materyali oluşturulmuştur. Aynı sürgünlerin devam eden üst aksamından (basit çelik) da yine $20 \mathrm{~cm}$ uzunlukta kesitler elde edilmiştir (Şekil 1). Klonların bir bölümü hazırlanmış olan \% 0.2 'lik IBA (Indole 3 Butirik Asit 2000 ppm) çözeltisine batırıldıktan sonra, bir bölümü ise IBA'ya batırılmadan kum havuzuna veya tarlaya dikilmiştir. Dikim işlemi Nisan ayı içerisinde kum havuzuna yaklaşı $8 \mathrm{~cm}$ derinlikte ve $8 \times 10 \mathrm{~cm}$ aralıklarla, tarla koşullarında ise, daha önceden hazır hale getirilen toprağa sıra arası $70 \mathrm{~cm}$, sıra üzeri $10 \mathrm{~cm}$ olacak şekilde dikilmiştir. Dikimden sonra gerek kum havuzu ve gerekse tarla toprağı sürekli nemli kalacak şekilde sulanmıştır. Deneme alanında tutan ve tutmayan klonların sayım işlemi dikimden yaklaşık 45 gün sonra yapılmış ve köklenen klonların oran $1 \%$ olarak hesaplanmıştır. Elde edilen köklenme oranı (\%) değerlerine açı (Arc sinüs) transformasyonu uygulanarak MSTAT-C istatistik paket programı yardımıyla tesadüf parsellerinde bölünen-bölünen bölünmüş parseller deneme desenine uygun olarak varyans analizi uygulanmıştır. Köklendirme ortamları ana parsel, genotipler alt parsel, klon kaynağı (basit çelik veya ökçeli çelik ) alt alt-parsel ve IBA uygulaması alt-alt-alt parsel olarak alınmıştır.
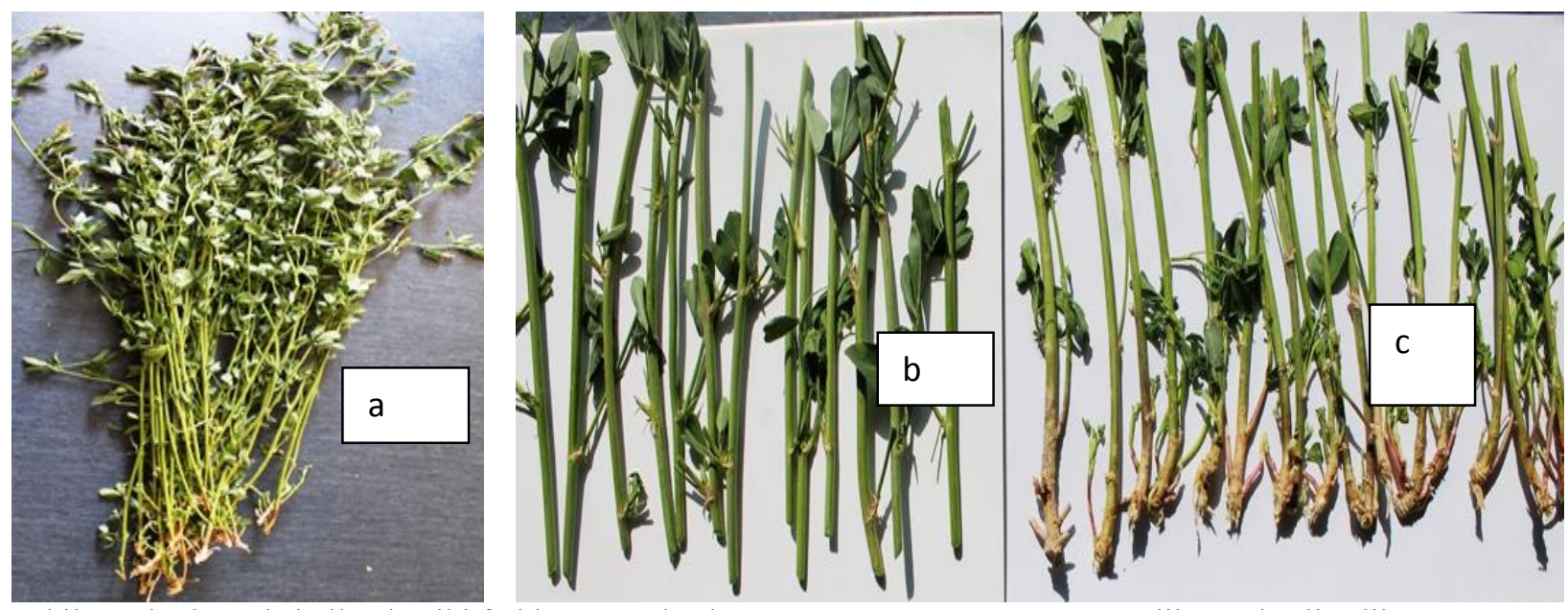

Şekil 1. Klonlamada kullanılan iki farklı yonca eksplantı (a) yonca bitkisi; b) basit çelik;c) ökçeli çelik 


\section{BULGULAR ve TARTIŞMA}

Araştırmada elde edilen verilere uygulanan varyans analizi sonuçları köklenme üzerine; ortam, genotip, IBA uygulmas1, genotip x ortam, ortam x eksplant, genotip x eksplant, ortam $x$ eksplant $x$ IBA uygulamas ve genotip $x$ ortam $x$ IBA uygulamas1 interaksiyonlarının istatistiksel olarak önemli derecede etki ettiğini göstermiştir. Farklı ortam-genotip-eksplanthormon kombinasyonları için saptanan köklenme oranı ortalamaları Çizelge 1'de verilmiştir.

Çizelge 1. Farklı yonca genotiplerinden alınan farklı eksplantların IBA uygulamalı veya uygulamasız koşullarda farklı ortamlardaki köklenme oranı ortalamaları (\%)

\begin{tabular}{|l|l|l|l|l|l|l|l|}
\hline & \multicolumn{2}{|c|}{ Ortam } & \multicolumn{2}{c|}{ Hormon } & \multicolumn{2}{c|}{ Eksplant } & \\
\hline Genotip/klon & Kum & Tarla & $\begin{array}{l}\text { IBA } \\
\text { uygulamal } 1\end{array}$ & $\begin{array}{l}\text { IBA } \\
\text { uygulamasız }\end{array}$ & $\begin{array}{l}\text { Ökçeli } \\
\text { çlik }\end{array}$ & Basit çelik & Ortalama \\
\hline $1(37-12)$ & $89.6 \mathrm{a}-\mathrm{d}^{3}$ & $60.4 \mathrm{~g}-1$ & $72.9 \mathrm{~d}-\mathrm{g}^{4}$ & $77.1 \mathrm{~b}-\mathrm{f}$ & $79.2 \mathrm{~b}-\mathrm{e}^{5}$ & $70.8 \mathrm{~d}-\mathrm{g}$ & $75.0 \mathrm{c}-\mathrm{e}^{*}$ \\
\hline $2(22-4)$ & $93.8 \mathrm{ab}$ & $58.3 \mathrm{~g}-1$ & $72.9 \mathrm{~d}-\mathrm{g}$ & $79.2 \mathrm{a}-\mathrm{f}$ & $77.1 \mathrm{c}-\mathrm{f}$ & $75.0 \mathrm{c}-\mathrm{f}$ & $76.0 \mathrm{c}-\mathrm{e}$ \\
\hline $3(22-10)$ & $89.6 \mathrm{a}-\mathrm{d}$ & $54.2 \mathrm{~h}-\mathrm{j}$ & $70.8 \mathrm{e}-\mathrm{g}$ & $72.9 \mathrm{~d}-\mathrm{g}$ & $70.8 \mathrm{~d}-\mathrm{g}$ & $72.9 \mathrm{~d}-\mathrm{f}$ & $71.9 \mathrm{c}-\mathrm{e}$ \\
\hline $4(14-3)$ & $91.7 \mathrm{a}-\mathrm{c}$ & $66.7 \mathrm{fg}$ & $72.9 \mathrm{~d}-\mathrm{g}$ & $85.4 \mathrm{a}-\mathrm{d}$ & $81.3 \mathrm{~b}-\mathrm{d}$ & $77.1 \mathrm{c}-\mathrm{f}$ & $79.2 \mathrm{bc}$ \\
\hline $5(26-12)$ & $95.8 \mathrm{ab}$ & $85.4 \mathrm{~b}-\mathrm{d}$ & $89.6 \mathrm{ab}$ & $91.7 \mathrm{a}$ & $87.5 \mathrm{a}-\mathrm{c}$ & $93.8 \mathrm{a}$ & $90.6 \mathrm{a}$ \\
\hline $6(16-11)$ & $93.8 \mathrm{ab}$ & $50.01-\mathrm{k}$ & $72.9 \mathrm{~d}-\mathrm{g}$ & $70.8 \mathrm{e}-\mathrm{g}$ & $70.8 \mathrm{~d}-\mathrm{g}$ & $72.9 \mathrm{~d}-\mathrm{f}$ & $71.9 \mathrm{c}-\mathrm{e}$ \\
\hline $7(14-6)$ & $97.9 \mathrm{a}$ & $72.9 \mathrm{ef}$ & $81.3 \mathrm{a}-\mathrm{e}$ & $89.6 \mathrm{ab}$ & $91.7 \mathrm{ab}$ & $79.2 \mathrm{~b}-\mathrm{e}$ & $85.4 \mathrm{ab}$ \\
\hline $8(19-8)$ & $89.6 \mathrm{a}-\mathrm{d}$ & $47.9 \mathrm{k}$ & $66.7 \mathrm{f}-\mathrm{h}$ & $70.8 \mathrm{e}-\mathrm{g}$ & $70.8 \mathrm{~d}-\mathrm{g}$ & $66.7 \mathrm{e}-\mathrm{h}$ & $68.8 \mathrm{ef}$ \\
\hline $9(5-11)$ & $85.4 \mathrm{~b}-\mathrm{d}$ & $41.7 \mathrm{k}$ & $56.3 \mathrm{~h} 1$ & $70.8 \mathrm{e}-\mathrm{g}$ & $72.9 \mathrm{~d}-\mathrm{f}$ & $54.2 \mathrm{~h}$ & $63.5 \mathrm{fg}$ \\
\hline $10(7-2)$ & $97.9 \mathrm{a}$ & 25.01 & 52.11 & $70.8 \mathrm{e}-\mathrm{g}$ & $58.3 \mathrm{gh}$ & $64.6 \mathrm{f}-\mathrm{h}$ & $61.5 \mathrm{~g}$ \\
\hline $11(8-11)$ & $95.8 \mathrm{ab}$ & $45.8 \mathrm{jk}$ & $72.9 \mathrm{~d}-\mathrm{g}$ & $68.8 \mathrm{e}-\mathrm{g}$ & $70.8 \mathrm{~d}-\mathrm{g}$ & $70.8 \mathrm{~d}-\mathrm{g}$ & $70.8 \mathrm{de}$ \\
\hline $12(23-9)$ & $79.2 \mathrm{de}$ & $72.9 \mathrm{ef}$ & $79.2 \mathrm{~b}-\mathrm{f}$ & $72.9 \mathrm{~d}-\mathrm{g}$ & $70.8 \mathrm{~d}-\mathrm{g}$ & $81.3 \mathrm{a}-\mathrm{d}$ & $76.0 \mathrm{c}-\mathrm{e}$ \\
\hline $13(21-1)$ & $81.3 \mathrm{c}-\mathrm{e}$ & $64.6 \mathrm{f}-\mathrm{h}$ & $79.2 \mathrm{a}-\mathrm{f}$ & $66.7 \mathrm{f}-\mathrm{h}$ & $72.9 \mathrm{~d}-\mathrm{f}$ & $72.9 \mathrm{~d}-\mathrm{f}$ & $72.9 \mathrm{c}-\mathrm{e}$ \\
\hline $14(1-10)$ & $91.7 \mathrm{a}-\mathrm{c}$ & $60.4 \mathrm{~g}-1$ & $77.1 \mathrm{~b}-\mathrm{f}$ & $75.0 \mathrm{c}-\mathrm{f}$ & $75.0 \mathrm{c}-\mathrm{f}$ & $77.1 \mathrm{c}-\mathrm{f}$ & $76.0 \mathrm{c}-\mathrm{e}$ \\
\hline $15(20-7)$ & $87.5 \mathrm{a}-\mathrm{d}$ & $66.7 \mathrm{fg}$ & $66.7 \mathrm{f}-\mathrm{h}$ & $87.5 \mathrm{a}-\mathrm{c}$ & $66.7 \mathrm{e}-\mathrm{h}$ & $87.5 \mathrm{a}-\mathrm{c}$ & $77.1 \mathrm{~cd}$ \\
\hline $16(29-11)$ & $79.2 \mathrm{de}$ & $41.7 \mathrm{k}$ & $60.4 \mathrm{~g}-1$ & $60.4 \mathrm{~g}-1$ & $56.3 \mathrm{~h}$ & $64.6 \mathrm{f}-\mathrm{h}$ & $60.4 \mathrm{~g}$ \\
\hline Ortalama & $\mathbf{9 0 . 0 A}^{1}$ & $\mathbf{5 7 . 2 B}$ & $\mathbf{7 1 . 5 B ^ { 2 }}$ & $\mathbf{7 5 . 7 A}$ & $\mathbf{7 3 . 3}$ & $\mathbf{7 3 . 8}$ & $\mathbf{7 3 . 6}$ \\
\hline
\end{tabular}

*) Aynı sütun içinde benzer harf ile gösterilen ortalamalar Duncan testine göre $\mathrm{P} \leq 0.05$ hata sinırları içinde birbirinden önemli derecede farklı değildir.

1)İki ortam ortalaması istatistiksel olarak $P \leq 0.05$ hata sınırları içinde birbirinden önemli derecede farklidir.

2) Hormonlu ve Hormonsuz uygulama ortalamaları istatistiksel olarak $\mathrm{P} \leq 0.05$ hata sinırları içinde birbirinden önemli derecede farklıdır.

3) Benzer harf ile gösterilen Genotip x Ortam kombinasyon ortalamaları Duncan testine göre göre $P$ $\leq 0.05$ hata sınırları içinde birbirinden önemli derecede farklı değildir.

4) Benzer harf ile gösterilen Genotip x Hormon kombinasyon ortalamaları Duncan testine göre göre $\mathrm{P}$ $\leq 0.05$ hata sınırları içinde birbirinden önemli derecede farklı değildir.

5) Benzer harf ile gösterilen Genotip x Exsplant kombinasyon ortalamaları Duncan testine göre göre $P$ $\leq 0.05$ hata sınırları içinde birbirinden önemli derecede farklı değildir.

Araştırmada yer alan genotiplerin kum ortamında ortalama köklenme oranı (\% 90) tarla ortamındakine göre (57.2) önemli derecede daha yüksek olmuştur. Genotiplerin kum ortamındaki ortalama köklenme oranlar1 \% 79.2-97.9, tarla ortamında ise \% 25.0-85.4 arasında değişmiştir. Genotipler kum ve tarla ortamında farklı köklenme oranlarına sahip olmuşlardır ve bu durum genotip $\mathrm{x}$ ortam interaksiyonunun ortaya çıkmasında etkili olmuştur. Kum ortamında 7-2 nolu genotip (\% 97.9) ilk sirada yer alırken, tarla ortamında en yüksek köklenme oranı ( $\%$ 85.4) $26-12$ nolu genotipte saptanmıştır.

IBA uygulanmayan eksplantların IBA uygulanan eksplantlara göre daha yüksek köklenme oranı göstermesi özellikle araştırmada yer alan 7-2 ve 5-11 nolu genotiplerin IBA'lı ortamda genel ortalamanın çok altında köklenme oranına sahip olmalarından kaynaklanmıştır. IBA uygulanması veya uygulanmamasına bağlı olarak incelenen genotiplerin köklenme oranları \% 52.1-91.7 arsasında değişmiş̧ir.

Genel olarak değerlendirildiğinde IBA uygulanmayan eksplantların ortalama köklenme oranı (\% 75.7) IBA uygulanan eksplantların ortalama köklenme oranına göre (\%71.5) önemli derecede yüksek bulunmuştur. IBA'lı ve IBA'sız uygulamaların her ikisinde de en yüksek köklenme oranı (sırasıyla \% 89.6- 
91.7) 26-12 nolu genotipte saptanmıştır. Araştırmada incelenen yonca eksplantlarının (ökçeli çelik veya basit çelik) köklenme oranı ortalamaları (\% 73.3 ve \% 73.8) istatistiksel olarak önemli bir farklılık göstermemiştir. Ancak, eksplantların köklenme oranı üzerindeki etkisi genotiplere bağlı olarak farklılık göstermiştir. Ökçeli çeliklerin köklenme oranı genotiplere bağlı olarak \% 56.3-91.7 arasında değişirken, basit çeliklerin köklenme oranı \% 54.2-93.8 arasında değişmiştir (Çizelge 1).

Uygulamalar içerisinde en yüksek ortalama köklenme oranına (\% 90.4) eksplantlar kum ortamına IBA uygulanarak dikildiğinde ulaşılmıştır. Bunu \% 89.6 oranla aralarında istatistiksel olarak önemli bir fark olmaksızın yine kum ortamında IBA sız uygulama izlemiştir.

Tarla koşullarında ise ortalama köklenme oranları (IBA siz \% 61.7, IBA l1 \% 52.6 ) kum ortamına göre önemli derecede daha düşük bulunmuştur (Çizelge 2).

Eksplantlar kum ortamında tarla ortamına göre önemli derecede daha fazla köklenme oranına sahip olmuşlardır. Kum ortamında basit çeliklerin ortalama köklenme oranı (\% 96.6) ökçeli çeliklerin ortalama köklenme oranına (\% 83.3) göre önemli oranda yüksek bulunmuştur. Tarla ortamında explantların ortalama köklenme oranı ökçeli çeliklerde ortalama \% 63.3 olarak bulunurken, bu değer basit çeliklerde ortamında $\% 51.0$ olarak belirlenmiştir.

Çizelge 2. Yonca genotiplerinden alınan farklı eksplantların IBA uygulamalı veya uygulamasız koşullarda farklı ortamlardaki köklenme oranı ortalamaları (\%)

\begin{tabular}{|l|l|c|}
\hline \multicolumn{2}{|l|}{ Uygulamalar } & Köklenme Oranları (\%) \\
\hline \multirow{4}{*}{ IBA } & 1-IBA uygulandıktan sonra- Kumda & $90.4 \mathrm{a}^{6}$ \\
\cline { 2 - 3 } & 2- IBA uygulamadan- Kumda & $89.6 \mathrm{a}$ \\
\cline { 2 - 3 } & 3- IBA uygulandıktan sonra- Tarlada & $52.6 \mathrm{c}$ \\
\cline { 2 - 3 } & 4- IBA uygulanmadan- Tarlada & $61.7 \mathrm{~b}$ \\
\hline \multirow{3}{*}{ Eksplant } & 1-Ökçeli çelik- Kumda & $83.3 \mathrm{~b}^{7}$ \\
\cline { 2 - 3 } & 2-Basit çelik- Kumda & $96.6 \mathrm{a}$ \\
\cline { 2 - 3 } & 3-Ökçeli çelik- Tarlada & $63.3 \mathrm{c}$ \\
\cline { 2 - 3 } & 4- Basit çelik- Tarlada & $51.0 \mathrm{~d}$ \\
\hline
\end{tabular}

6) Benzer harf ile gösterilen Ortam x Hormon kombinasyon ortalamaları Duncan testine göre göre $\mathrm{P}$ $\leq 0.05$ hata sınırları içinde birbirinden önemli derecede farklı değildir.

7) Benzer harf ile gösterilen Ortam X Eksplant kombinasyon ortalamaları Duncan testine göre göre $\mathrm{P}$ $\leq 0.05$ hata sinırları içinde birbirinden önemli derecede farklı değildir.

Genel olarak değerlendirildiğinde, tarla koşullarında basit çeliklere IBA uygulamasının köklenme üzerine olumsuz etki yaptı̆̆ 1 söylenebilir. Zira belirtilen ortamda adi çeliklere IBA uygulandığında ortalama köklenme oranı, IBA uygulanmayan ve aynı ortamda kültürü yapılan basit çeliklerin ortalama köklenme oranına göre daha düşük bulunmuştur. Tarla koşullarında ise ökçeli çeliklere uygulanan IBA'nın köklenme üzerine olumlu etki yaptığı tespit edilmiştir. Çünkü ökçeli çeliklere IBA uygulaması ile ortalama köklenme oranı, IBA uygulanmadığı durumda hesaplanan ortalama değere göre önemli derecede yüksek bulunmuştur.

\section{SONUÇ}

Araştırma bulguları, Çukurova bölgesi ekolojik koşullarında IBA uygulamasının kum ortamında basit çeliklerde, tarla koşullarında ise ökçeli çeliklerde köklenme oranını önemli derecede yükselttiğini ortaya koymuştur.

\section{KAYNAKLAR}

Avcı M, A. Aktaş, N. Kılıçalp and R. Hatipoğlu, 2011. Development of synthetic cultivar of alfalfa (Medicago sativa L.) on the basis of polycross progeny performance in the Southern Anatolia., Journal Of Food Agriculture \& Environment (ISI), 404-408 pp.

Bernadette J, Christian H, and Christian E 2000. Within and Among Cultivar Genetic Variation in Alfalfa: Forage Quality, Morphology and Yield. Crop Science. 40:365369.

Busbice T.H, Hill R.R, Carnahan H.L 1972. Genetics and Breeding Procedures (In. C.H. Hanson Editor). Alfalfa Seience and Tech. ASA Publ. No: 15, p 283-314.

Poehlman J.M, and Sleper D.A 1995. Breeding Field Crops. Fourth Edition Iowa State Univ. Ames.

El-Tabbakh A. E (1965). Rooting Alfalfa Stem Cuttings. Progressive Agriculture in Arizona Vol. 17, No 2. College of Agriculture, University of Arizona. 